\title{
FERRO-VORTEX APPARATUS
}

\author{
Andrey Adoshev, Sergey Antonov, Sergey Yastrebov, Mikhail Melnikov \\ Stavropol State Agrarian University, Russia \\ adoshev@mail.ru, antonov_serg@mail.ru,yastrsergej@yandex.ru,mikhail_melnikov@list.ru
}

\begin{abstract}
The ferro-vortex apparatus relates to devices for electro-mechanical processing of liquid, bulk and other blends that can be used in agriculture, medicine, chemical, oil and gas industry, communal services and other areas. The article discusses the features of the use of the ferro-vortex apparatus for handling liquid manure. Energy of rotating electromagnetic field is concentrated in a small volume of the working zone of the apparatus. As the source of infections and invasions liquid manure is dangerous not only to farmyards and premises of this livestock enterprise, but, getting to ground waters, becomes a source of epidemics for persons and animals in far located territories. One of the reliable solutions of this problem is the use of alternative lines of treatment of liquid manure, the main node of which is the apparatus of the vortex layer with the inductor of the electromagnetic field of a cylindrical shape. The disadvantages of such apparatus and devices created on its basis include low energy performance, uneven electromagnetic field in the working area, non-uniform processing quality of manure along the radius of the working area. The ferro-vortex apparatus was developed to eliminate the above drawbacks. To create a rotating electromagnetic field in the apparatus the inductor of axial shape is used. The article shows the advantage of using devices with axial arrangement of the electromagnetic elements to implement the features of a vortex layer of ferromagnetic particles in the working area during the processing of liquid manure of livestock enterprises.
\end{abstract}

Keywords: apparatus of the vortex layer, vortex layer of ferromagnetic particles, processing of liquid manure.

\section{Introduction}

Hydro-removal of manure is very common on livestock farms. This leads to considerable dilution with water and conversion into low-concentration liquid manure (LM). Its volume is five times greater than the number of the source of manure. This greatly increases the time of survival in the causative agents of infectious diseases. Permanent decontamination of all produced on the farm manure becomes necessary regardless of veterinary welfare of the farm.

In this regard, disinfection of liquid manure is important. Along with traditional methods of disinfection there are available and relatively new ones, based on an integrated exposure to electromagnetic fields and mechanical damage. However, the drawbacks of the devices for implementing such methods limit their implementation.

In the All-Russian Research Institute of Mechanization of Animal Husbandry (ARSRIMAH) a processing line was offered that is an important link, which is the apparatus of the vortex layer (AVS) of a cylindrical execution, which destroys disease-causing microorganisms, helminths, their eggs and weed seeds, with simultaneous crushing mechanical particles of manure $[1 ; 2]$. The reason for the positive effects is due to a change in the structure of water and suspended matter under the influence of a magnetic field.

The working chamber of AVS, as shown in Fig. 1, is a tube of non-magnetic material 1 mounted in the bore of the inductor 2, placed in the case 3. With the help of the inductor 2 in the working chamber a rotating electromagnetic field is generated. The working bodies are ferromagnetic particles 5 rotating under the influence of the field in the working area removable insert of non-magnetic material 4.

When ferromagnetic particles are placed in the working chamber placed in a device creating a rotating electromagnetic field in the working area of this chamber, they come into a complex motion, creating a vortex layer [3].

Processing passed through the chopper LM humidity 95-97\% in the rotating electromagnetic field in the apparatus with a vortex layer of AVS-150 with ferromagnetic particles in the working area provides disinfection from vegetative pathogenic microorganisms over 60 , while increasing the mass of the ferromagnetic particle surface disinfection for $30 \mathrm{~s}$. The use in the production line of several AVS allows to decontaminate the manure runoff in the stream [4]. 


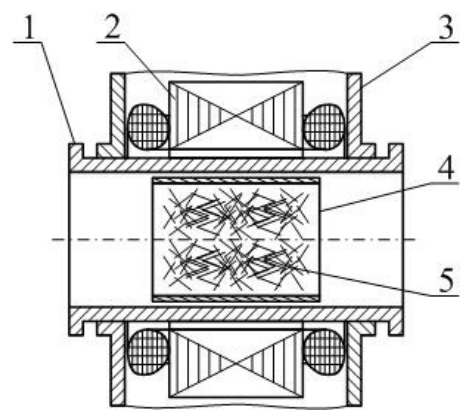

Fig. 1. Design of apparatus of vortex layer: 1 - tube of nonmagnetic material, 2 - inductor; 3 - case; 4 - removable insert; 5 - ferromagnetic particles

The disadvantages of the AVS, as well as the devices created on its basis [3; 5], are: low energy indicators due to a large non-magnetic gap in the diameter of the inductor; the electromagnetic field in the working area is uneven - induction near the walls of the working area is much larger than along the central axis, which worsens the quality of manure handling and contributes to energy losses; the concentration of ferromagnetic particles and the quality of manure treatment along the radius of the working zone are not uniform - the maximum at its walls and the minimum along its axis, which requires the use of several devices to disinfect manure in the stream; intensive wear of ferromagnetic particles and the inner surface of the working area.

In this connection, it became necessary to create an apparatus that would eliminate these drawbacks, with equal productivity and reduced mass, dimensions and cost of the device.

\section{Materials and methods}

In the proposed design of the ferro-vortex apparatus (FVA), there are constructive elements, which meet the basic requirements of the realization of the potential of a vortex layer: electromagnetic system (inductor) - in our case an axial rather than cylindrical inductor is used to create a rotating electromagnetic field; ferromagnetic particles driven by a rotating magnetic field; the magnetic field closes through the axial magnetic core; the working area bounded by the inner surface of the lid of the reaction chamber and the protective casing of the axial magnetic core from a non-magnetic material [6-10].

The constructive scheme of the active part AVS of the cylindrical execution and FVA of the axial execution is determined by the shape of the working zone, the mutual spatial location and the number of active elements of the inductor, the value of magnetic induction in the central part of the working area when idling, i.e. in the absence of ferromagnetic particles. In this case, it is necessary to take into account that in the AVS inductor covers the working chamber. Therefore, the comparison of possibilities of devices of two types will be made on the example of magnetic inductors with their windings.

Equivalent in electromagnetic relation to the dimensions of axial (FVA) and cylindrical (AVS) devices is determined based on the conditions of equality of their electromagnetic power. In this case, the calculated diameter and the active length of the cylindrical and axial models are equal and are defined through the outer and inner diameters of the axial ratios of the device [11-13]:

$$
\left.\begin{array}{l}
D_{c}=D_{\text {mid }}=0.5\left(D_{\text {out }}+D_{\text {in }}\right) \\
l_{c}=l_{\delta}=0.5\left(D_{\text {out }}-D_{\text {in }}\right)
\end{array}\right\},
$$

where $D_{c}$-diameter of the inner bore inductor of the cylindrical apparatus;

$D_{\text {mid }}, D_{\text {out }}, D_{\text {in }}$ - middle, outer and inner, respectively, the diameters of the active surface of the inductor of the axial apparatus;

$l_{c}$ - active core length of the inductor of the cylindrical apparatus;

$l_{\delta}-$ active length of the inductor axial apparatus.

The condition of equality of the electromagnetic power is also consistent with equality (in case of equality of electromagnetic loads) of the magnetic fluxes and the number of turns of FVA and AVS: 


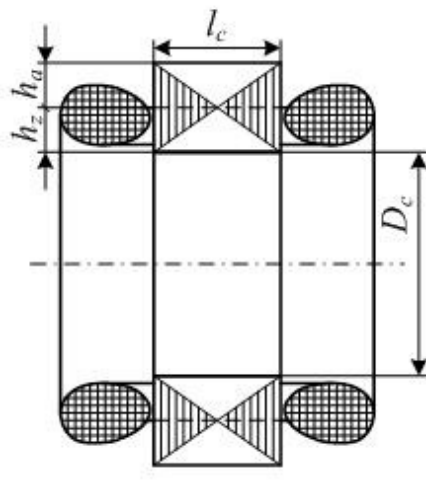

a)

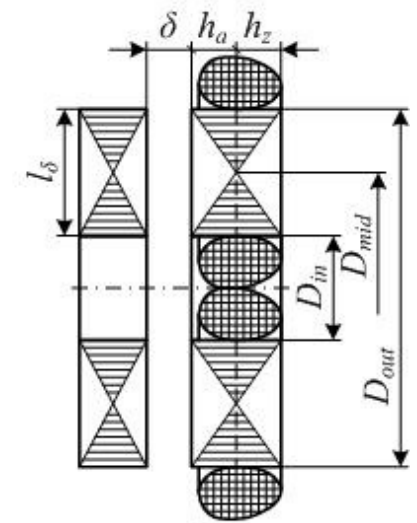

b)

Fig. 2. Comparison of cylindrical and axial designs of the apparatus:

$\mathrm{a}$ - radial active part; $\mathrm{b}$ - axial active part

$$
\left.\begin{array}{l}
\Phi_{\delta a}=\Phi_{\delta c}=\Phi_{\delta} \\
w_{a}=w_{c}=w
\end{array}\right\}
$$

where $\Phi_{\delta a}, \Phi_{\delta c}$ - magnetic fluxes of the axial and cylindrical device in the working gap; $w_{a}, w_{c}$ - number of turns of the axial and cylindrical device.

For the legitimacy of comparison of the volumes of AVS and FVA it is required in addition compliance with the conditions (1), (2) upholding the equality of the heights of the active layers (of teeth), current densities and dimensions of the grooves of the windings of the magnetic cores of the inductor axial and cylindrical designs, the equality of cross sections and heights of yokes of magnetic circuits of the inductors:

$$
\left.\begin{array}{l}
h_{s 1 a}=h_{s 1 c}=h_{s 1} ; \\
b_{s 1 a}=b_{s 1 c}=b_{s 1} ; \\
h_{a 1 a}=h_{a 1 c}=h_{a 1}
\end{array}\right\},
$$

where $h_{s l a}, h_{s l c}-$ height slots of a magnetic core of the inductor FVA and inductor AVS;

$b_{s l a}, b_{s l c}$ - width slots of the magnetic core of the inductor FVA and inductor AVS;

$h_{a l a}, h_{a l c}$ - height of the yokes of the magnetic core of the inductor FVA and inductor AVS.

A comparison of the volumes of active materials is carried out for rectangular slots of magnetic cores of inductors in accordance with Fig. 2 (a, b).

The volume of the yoke of the magnetic core of the inductor axial apparatus:

$$
V_{a 1 a}=\frac{\pi D_{\text {out }}^{2}}{4} h_{a 1}-\frac{\pi D_{\text {in }}^{2}}{4} h_{a 1}=\frac{\pi h_{a 1}}{4}\left(D_{\text {out }}^{2}-D_{\text {in }}^{2}\right)=\pi D_{\text {mid }} l_{\delta} h_{a 1},
$$

where $h_{a l}$ - is the height of the yoke of the magnetic circuit of the inductor axial apparatus.

The volume of the teeth of the magnetic core of the inductor of the axial apparatus:

$$
V_{z l a}=z_{1} b_{z l m i d} l_{\delta} h_{s l}=z_{I}\left(\frac{\pi D_{\text {mid }}}{z_{1}}-b_{s l}\right) l_{\delta} h_{s l},
$$

where $b_{z l m i d}$ - average width of teeth of the magnetic circuit of the inductor axial apparatus;

$h_{s l}$ - height slot of the magnetic circuit of the inductor axial apparatus;

$z_{1}-$ number of teeth of the magnetic circuit of the inductor axial apparatus.

The volume of the yoke of the inductor of a cylindrical apparatus:

$$
V_{a 1 c}=\frac{\pi}{4} l_{\delta}\left(D_{m i d}+2 h_{s 1}+2 h_{a 1}\right)^{2}-\frac{\pi}{4} l_{\delta}\left(D_{m i d}+2 h_{s 1}\right)^{2}=\pi D_{m i d} h_{a 1} l_{\delta}+\pi h_{a 1} l_{\delta}\left(2 h_{s 1}+h_{a 1}\right) \text {. }
$$


The volume of the inductor teeth of a cylindrical apparatus:

$$
V_{z 1 c}=z_{1}\left\{\left(\frac{\pi D_{m i d}}{z_{1}}-b_{s 1}\right)+\left[\frac{\pi\left(D_{m i d}+2 h_{s 1}\right)}{z_{1}}-b_{s 1}\right]\right\} \frac{h_{s 1} l_{\delta}}{2}=z_{1}\left(\frac{\pi D_{m i d}}{z_{1}}-b_{s 1}\right) h_{s 1} l_{\delta}+\pi h_{s 1}^{2} l_{\delta} .
$$

The volume of steel of the magnetic circuit of the inductor of the axial apparatus:

$$
V_{S a}=\pi D_{m i d}^{2} h_{a 1} l_{\delta}+V_{z 1 a},
$$

where $V_{z 1 a}-$ volume of teeth of the magnetic core of the inductor axial apparatus.

The volume of steel of the cylindrical inductor apparatus:

$$
V_{S c}=\pi D_{\text {mid }} h_{a 1} l_{\delta}+\pi h_{a 1} l_{\delta}\left(2 h_{s 1}+h_{a 1}\right)+V_{z 1 c},
$$

where $V_{z l y}$ - volume of the teeth of the inductor of the cylindrical apparatus.

A comparison of the volumes of the magnetic cores of the inductor (8) and (9) two performances of the apparatus shows that the volume of the steel of the axial inductor is used better than the volume of the steel of the cylindrical inductor [14]:

$$
V_{S a}=V_{S c}-\Delta V_{S},
$$

where $\Delta V_{S}-$ volume reduction of the steel magnetic core axial inductor relative to the volume of the cylindrical inductor:

$$
\Delta V_{S}=\pi h_{a 1} l_{\delta}\left(2 h_{s 1}+h_{a 1}\right)+\pi h_{s 1}^{2} l_{\delta} .
$$

Substitution in equation (10) gives:

$$
\begin{gathered}
V_{S a}=V_{S c}-\left(\pi l_{\delta} h_{a 1}\left(2 h_{s 1}+h_{a 1}\right)+\pi l_{\delta} h_{s 1}^{2}\right)= \\
=V_{S c}-\pi l_{\delta}\left(2 h_{a 1} h_{s 1}+h_{a 1}^{2}+h_{s 1}^{2}\right)=V_{S c}-\pi l_{\delta}\left(h_{a 1}+h_{s 1}\right)^{2}
\end{gathered} .
$$

Under the conditions (1) and (2) the volumes of material of the windings of the magnetic cores of the inductors FVA and ABC are approximately equal $[11 ; 15]$. However, due to the fact that in the cylindrical apparatus the winding of the inductor relative to the diameter $D_{\text {mid }}$ is located on the average diameter $\left(D_{\text {mid }}+h_{s I}\right)$ for the frontal parts, and the fronts are bent towards the outer diameter of the yoke of the inductor, the average length of the winding, the volume of the material and the electrical resistance of the windings of the inductor of the cylindrical apparatus slightly exceed the analogous values of the equivalent axial apparatus, i.e.:

$$
V_{w 1 c} \geq V_{w 1 a} ; r_{1 c} \geq r_{1 a},
$$

where $V_{w l c}, V_{w l a}$ - volume of material of the windings of the inductor AVS and the magnetic core of the inductor FVA;

$r_{l c}, r_{l a}$ - electrical resistance of the windings of the inductor AVS and the magnetic core of the inductor FVA.

The use of the apparatus with axial form of the active part is more rational in this case.

\section{Results and discussion}

Fig. 3 shows a section of the FVA with an axial arrangement of the active elements of the magnetic circuit, designed to eliminate these shortcomings.

Explanations to the principle of the operation of the ferro-vortex apparatus are shown in Fig. 4.

After applying the supply voltage to the winding in it an alternating current creates an alternating magnetic flux, which passes in the axial direction from the magnetic core of the inductor, through the working area of the working chamber and is located axially of the magnetic core. After that, the magnetic flux returns through the working area and closes the magnetic circuit of the inductor. 


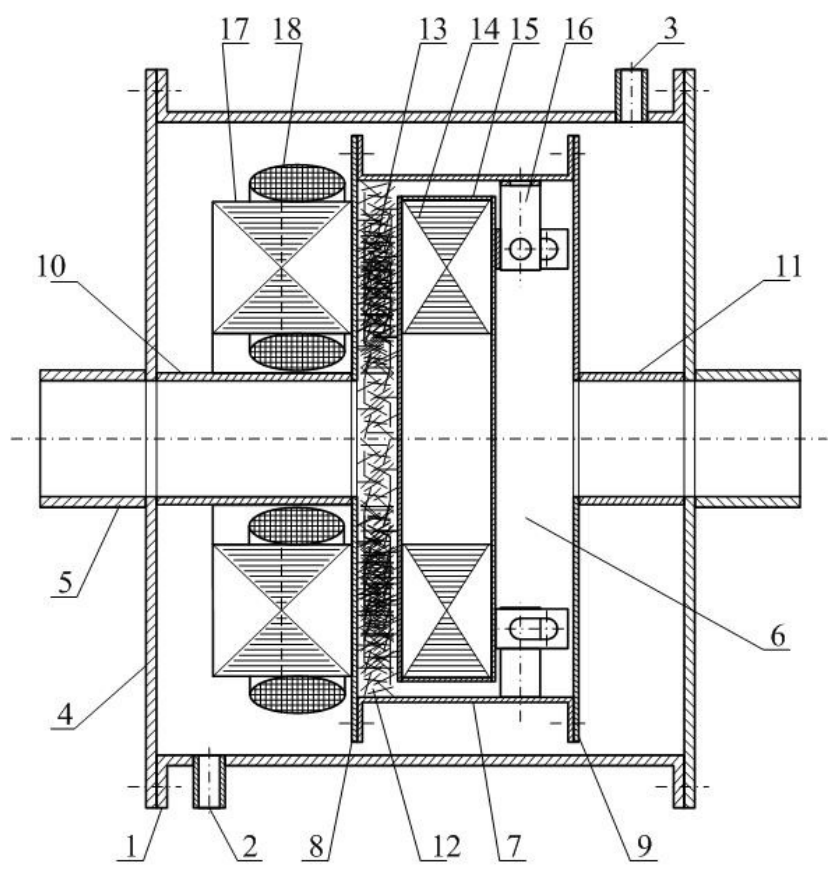

Fig. 3. Ferro-vortex apparatus: 1 - body; 2, 3-pipes for supplying and discharging the cooling medium; 4 - housing cover; 5 - pipes of the housing; 6 - working chamber; 7 - cylindrical body of the

working chamber; 8, 9- cover of the working chamber; 10, 11 -inlet and outlet nozzles of the working chamber; 12 - working area of the working chamber; 13 - ferromagnetic particles; 14 - axial magnetic core; 15 - casing of the axial magnetic core; 16 - mounting system; 17 - magnetic inductor; 18 - winding

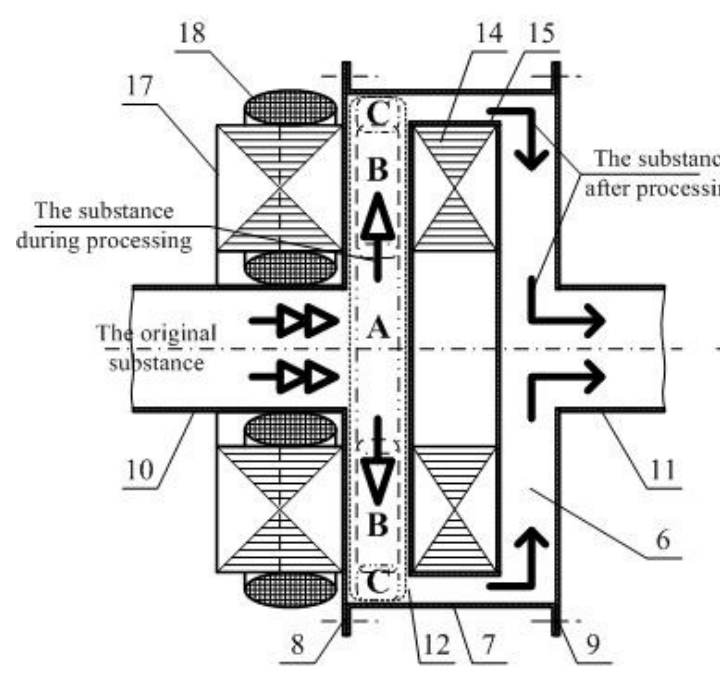

a)

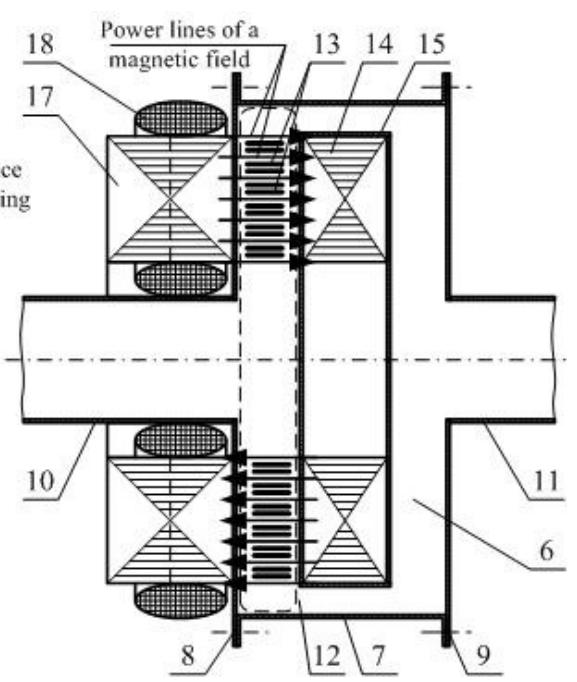

b)

Fig. 4. Explanations to the principle of operation of the ferro-vortex apparatus

A rotating electromagnetic field arises in the working zone, entraining ferromagnetic particles. The initial LM from the inlet of the working chamber enters the inner part A of the working area of the working chamber conditionally restricted inner diameter of the magnetic core of the inductor. In this part the density of the vortex layer of ferromagnetic particles is insignificant as they come in after the collision with other particles and with the working surfaces of the working chamber. Processed LM, mixing by means of a complex of forces acting on the particles, acquires rotational motion. Under the pressure of the incoming source being processed LM enters the area B working area of the working chamber, relatively limited external and internal diameters of the magnetic core of the inductor. 
In the stacked magnetic core of the inductor taken of the design, each layer of magnetic material is separated by a layer of insulation. In this case, each layer of the magnetic core of the inductor can be conditionally regarded as an elementary section of the pole creating a flow with its own lines of force.

The path of the magnetic lines of the field from the inductor magnetic core to the axial magnetic core and back in the area B of the working area of the working chamber is equal-limited and much less than the path overcome by the power lines in the cylindrical devices. Consequently, the electromagnetic field produced by these lines is more homogeneous, and the values of the magnetic induction and density of the vortex layer (during operation) are maximal.

In the volume of section B the main processing of LM transpires.

Ferromagnetic particles in the vortex layer form separate elemental layers, shown in Fig. 4, b and located at a distance from each other along the lines of the force of the magnetic field. Breakthrough of the particles from layer to layer is possible due to their collisions and the pressure of the incoming processed LM. Since the electromagnetic field on the plot B of the working area of the working chamber is uniform, the ferromagnetic particles are not attracted to the working surfaces of the working chamber and are evenly distributed throughout the volume of the plot along the magnetic field lines, which eliminates the leakage of the original LM untreated, in continuous technological process. The destruction of the surfaces of the cover of the working chamber and the casing of the axial magnetic core is not due to a shock, and due to the friction on their layer of particles, because the amplitude and impact force in such circumstances is minimal.

A homogeneous electromagnetic field in the vortex layer of plot B allows you to keep the bulk of ferromagnetic particles and prevents their leakage to the area $\mathrm{C}$, conditionally limited by the outer diameter of the inductor magnetic core and the inner surface of the cylindrical body of the working chamber.

The magnitude of the magnetic induction and, consequently, the density of the vortex layer on the plot of $\mathrm{C}$ is minimal. Therefore, the forces applied to the particles during their impact on the inner surface of the cylindrical body of the working chamber remote from the magnetic circuit do not lead to significant wear and tear.

After the area of $\mathrm{C}$ the treated LM flowing around the surface casing axial magnetic circuit through the outlet nozzle is supplied for further use.

\section{Conclusions}

The area of the annular gap between the inner diameter of the cylindrical housing of the working chamber and the outer diameter of the casing of the axial magnetic core is not less than the sectional area of the inlet branch pipe of the working chamber, which prevents the loss pressure of the treated LM in the working chamber preventing the removal of ferromagnetic particles with the treated stream LM.

Improving the energy indicators of FVA in comparison with the devices of the cylindrical design happens thanks to reduction of the non-magnetic gap between the magnetic conductor of the inductor and axial magnetic conductor, which leads to a decrease in the magnetomotive force of the magnetic chain and the magnetizing current of FVA, thanks to what its power factor - $\cos \varphi$ increases (with 0.20.4 at AVS to $0.65-0.75$ at FVA) and losses in the winding of the inductor magnetic conductor decrease.

\section{References}

1. Артюшин А.А., Гриднев П.И., Вершинин Н.П., Елисеева В.Е. Концепции создания безотходных технологий утилизации навоза (Concepts for the creation of non-waste technologies for manure utilization). Mechanized technology for harvesting and preparing manure for use: collection of scientific works. Podolsk: ARSRIMAH, 1989. pp. 154-159. (In Russian).

2. Гриднев П.И. Вопросы создания экологически безопасных технологий утилизации навоза (The questions of creation of ecologically safe technologies of recycling of manure). Mechanization and electrification of agriculture, 1994, No. 11. pp. 11-15. (In Russian). 
3. Логвиненко Д.Д., Шеляков О.П. Интенсификация технологических процессов в аппаратах вихревого слоя (Intensification of technological processes in apparatus of the vortex layer). Kiev: Technique, 1976. 143 p. (In Russian).

4. Ветеринарно-санитарные правила подготовки к использованию в качестве органических удобрений навоза, помета и стоков при инфекционных и инвазионных болезнях животных и птицы: Письмо Департамента ветеринарии Минсельхозпрода РФ № 13-7-2/1027 (Veterinary-sanitary rules of preparation for use as organic fertiliser of manure, litter, and wastewater at infectious and parasitic diseases of animals and birds: the Letter of the veterinary Department of the Ministry of agriculture of the Russian Federation No. 13-7-2/1027). 04.08.1997. (In Russian).

5. Вершинин, Н.П. Установки активации процессов. «Использование в промышленности и в сельском хозяйстве. Экология» (The device of activation of processes. "A use in industry and in agriculture. Ecology”). Rostov-on-Don, 2004. 314 p. (In Russian).

6. Адошев А.И., Коваленко В.В. Ферровихревой аппарат для обеззараживания жидкого навоза (The ferro-vortex apparatus for disinfection of liquid manure). Methods and technical means of improving the efficiency of the use of electricity in agriculture: collection of scientific works. Stavropol: AGRUS, 2006. pp. 114-117. (In Russian).

7. Адошев А.И. Ферровихревой аппарат для обработки жидкого навоза (The ferro-vortex apparatus for processing liquid manure). Rural mechanic, 2007, No. 6. pp. 32-33. (In Russian).

8. Адошев А.И., Антонов С.Н. Применение аксиального ферровихревого аппарата для гомогенизации жидкого навоза (The application of axial ferro-vortex apparatus for homogenization of liquid manure). Methods and means of increase of efficiency of use of electrical equipment in industry and agriculture: collection of scientific works. Stavropol, 2009. pp. 85-92. (In Russian).

9. Адошев А.И., Коваленко В.В. Ферровихревой аппарат (The ferro-vortex apparatus). Patent (RU) int. cl. B01F 13/08, No. 2323040. Available at http://www.freepatent.ru/patents/2323040 Recieved for publication December 25, 2006. Accepted after corrections April 27, 2008. (In Russian).

10. Адошев А.И., Коваленко В.В., Бушуев Е.Н. Аксиальный ферровихревой аппарат для обработки жидкого навоза и сточных вод (Axial ferro-vortex apparatus for processing liquid manure and wastewater). The utility model (RU) IPC B01F13/08, A01C3/00, No. 66222. Available at http://www.freepm.ru/Models/66222 Recieved for publication February 4, 2007. Accepted after corrections October 9, 2007. (In Russian).

11. Игнатов В.А., Вильданов К.Я. Торцевые асинхронные электродвигатели интегрального изготовления (Butt-end asynchronous electric motors of the integral making). Moscow: Energoatomizdat, 1988. 301 p. (In Russian).

12. Адошев А.И. Выбор конструкции индуктора ферровихревого аппарата (The choice of design of the inductor of ferro-vortex apparatus). Methods and means of increase of efficiency of use of electrical equipment in industry and agriculture: collection of scientific works. Stavropol, 2009. pp. 72-77. (In Russian).

13. Адошев А.И., Ивашина А.В. Особенности расчета индуктора ферровихревого аппарата (Features of calculation of the inductor of ferro-vortex apparatus). Methods and means of increase of efficiency of use of electrical equipment in industry and agriculture: collection of scientific works. Stavropol, 2010. pp. 8-13. (In Russian).

14. Казанский В.М., Зонов В.Н., Британчук В.М. К вопросу о сравнении асинхронных электродвигателей торцевого и цилиндрического исполнения малой мощности (То the question about comparison of asynchronous electric motors of butt-end and cylindrical execution of small-yield). Asynchronous micromachines. Materials interuniversity scientific conference. Kaunas, 1969. pp. 212-216.

15. Адошев А. И. Ферровихревой аппарат для обеззараживания жидкого свиного навоза (Тhe ferro-vortex apparatus for disinfection of liquid pig manure): dis.... cand. tech. sciences: Stavropol, 2011. 191 p. (In Russian). 